\title{
14
}

\section{Using Annual Hydrographs to Determine Effective Impervious Area}

Troy Jones, Chris Johnston and Craig Kipkie

Reducing the amount of directly connected impervious areas improves watercourse health and increases the potential for sustainable fish communities in streams. It also reduces the impacts of frequently-occurring rainfall-runoff events, and shifts watercourse hydrology closer to pre-development conditions. There is increasing focus on low impact development (LID) strategies as a means of improving watercourse health. Accurately determining the reduction of effective impervious area (EIA) has become crucial for assessing the effectiveness of these strategies. Quantifying EIA is also essential in developing and calibrating hydrologic models. In addition, it is important to test the effectiveness of LID strategies over the entire year, to take into account the large variability in antecedent conditions. Continuous simulation models focus on all events throughout the year, and not just a large design event.

Although several methods exist for measuring EIA, they tend to overestimate the effectiveness of LID strategies in wet climates when soils are saturated for a significant portion of the year. An annual hydrograph method is proposed to determine EIA. This involves using existing gauged creek systems and rainfall records from rainfall gauging networks. This enables the use of available data to determine a watershed's response to rainfall throughout the year, and thereby compute a year-round EIA. The results of this type of analysis will help to assess the effect of implementing LID strategies for existing or proposed developments, particularly for areas with wet climates.

Jones, T., C. Johnston and C. Kipkie. 2003. "Using Annual Hydrographs to Determine Effective Impervious Area." Journal of Water Management Modeling R215-14. doi:

10.14796/JWMM.R215-14.

(C) CHI 2003 www.chijournal.org ISSN: 2292-6062 (Formerly in Practical Modeling of Urban Water Systems. ISBN: 0-9683681-7-4) 


\subsection{Impervious Area - Why Do We Care?}

There are three primary reasons why an accurate estimate of impervious area is important. These three reasons are:

- to quantify watershed health;

- to develop more accurate continuous simulation hydrologic models; and

- to measure the effectiveness of strategies that are designed to infiltrate as much rainfall as possible before runoff occurs.

\subsubsection{Environmental Impacts of Increasing Impervious Area}

The relationship between imperviousness and environmental degradation has been well documented by Schueler (1995). With increasing imperviousness, it has been found that runoff peaks and volumes, bank erosion, and water temperature increase while water quality, fish populations, and macro-invertebrate populations decrease. Therefore, quantifying imperviousness is important to establish a relative ranking of watershed health.

\subsubsection{Hydrologic Modeling}

Hydrologic models typically require imperviousness as an input parameter, whether it is directly or indirectly required. In particular, an estimate of the directly connected impervious area on an annual basis is critical for an accurate continuous simulation of a watershed's response to rainfall.

\subsubsection{Effectiveness of Low Impact Development Strategies in a Wet Climate}

To reduce the environmental impacts of directly connected impervious areas to the drainage system and downstream watercourses, low impact development (LID) strategies such as green roofs, porous surfaces, grassy swales, and disconnected roof leaders are increasingly recommended. LIDs are stormwater management best management practices that are employed at the site level. These methods typically involve capturing frequently occurring rainfall events and preventing runoff through infiltration, evaporation, and transpiration. This increasing focus on LID strategies makes assessment of their effectiveness and suitability very important. In particular, for areas with high annual rainfall volumes such as the coastal areas of western $\mathrm{BC}$ and western Washington, the 
effectiveness of these strategies where soils are saturated for a significant portion of the winter is of great interest. The effectiveness of these strategies on an annual basis is more significant than their effectiveness during an individual event or a specific design storm. Therefore, measuring the effectiveness of these strategies will provide information that will estimate the reduction in directly connected impervious area that can be expected for each type of LID strategy.

\subsection{Total and Effective Impervious Area}

Total impervious area (TIA) is typically expressed as the sum of all impermeable surfaces within a defined drainage area, and is expressed as a percentage of the entire drainage area. EIA is typically expressed as the portion of the TIA that is directly connected to a piped drainage system or a watercourse, and is also expressed as a percentage of the entire drainage area. Some typical and alternative methods for determining both TIA and EIA are described below.

\subsubsection{Typical methods for determining TIA}

The two most commonly used methods for determining TIA use the following:

- land-use or zoning mapping; and

- aerial or satellite photography.

Both of these methods are discussed in more detail in this section.

\section{Land-use/zoning mapping combined with typical impervious factors}

The use of land-use or zoning mapping that is typically available from most municipal governments is a commonly used method to determine TIA. A watershed boundary is delineated on the land-use or zoning map and typical impervious percentages are applied to each land-use or zoning designation. Typical impervious percentages are available from a number of sources, but local knowledge of developments and verification of the impervious percentages must be used to increase the accuracy of this method.

\section{Aerial/satellite photography}

Visual interpretation or pixel identification techniques can be used on aerial and satellite photographs to determine TIA (Zandbergen and Schreier, 2000). Visual interpretation involves analyzing an aerial photograph of the watershed area and 
measuring the impervious surfaces. Pixel identification techniques can also be used to digitally analyze aerial or satellite photographs to determine the total impervious area. Calibrating or training the pixel identification routines on known sub-basins within the watershed must be completed to increase the accuracy of the TIA estimates.

\subsubsection{Alternative Methods for Determining TIA}

Ground surveys and stereo-photogrammetry methods are also available for determining TIA, but are not commonly used because they are labour intensive and expensive (Zandbergen and Schreier, 2000). However, where existing information exists, these two methods will provide more accurate estimates of the TIA.

\section{Ground surveys}

Ground surveys to determine impervious areas are not commonly used primarily due to the expense of completing the survey. A ground survey is labour intensive, yet it provides the most accurate measure of TIA. At the site level, this is an effective way to determine TIA.

\section{Stereo-photogrammetry}

Stereo-photogrammetry is an accurate method that uses aerial photos. A photogrammetrist synthesizes the aerial photos to remove distortion and delineate buildings, roads, and other impermeable surfaces. This delineated digital layer can then be analyzed to determine the TIA. This method is labour intensive and requires specialized equipment. As a result, it is expensive and not commonly used (Zandbergen and Schreier, 2000).

\subsubsection{Determining EIA}

This section focuses on three methods most commonly used to determine EIA. These are : field measurement, empirical equations, and calibrated computer models.

\section{Field measurement}

EIA can be determined through a field survey. The field survey includes cataloguing each impervious surface to determine whether or not it is directly connected to a pipe, ditch or other impervious surface that is itself connected. 
The areas that are not directly connected are then subtracted from the TIA to calculate the EIA. This method relies on the judgment of the surveyor to accurately determine the direct and indirect connections and may only be valid at the time of the survey. Soil saturation may cause some impervious areas to become "connected" during larger rainfall events and these areas are difficult to predict.

\section{Empirical equations}

Empirical equations for determining EIA have been developed as part of several different studies. One relationship was proposed by Alley and Veenhuis (1983) based on work completed for highly urbanized drainage areas in Denver, Colorado. They proposed the equation:

$$
E I A=0.15 \times T I A^{1.41}
$$

Laenen (1983) developed another relationship based on work completed in Oregon on more than 40 watersheds. The equation proposed was:

$$
E I A=3.6+0.43 \times T I A
$$

The data used by Laenen to develop Equation 14.2 was re-analyzed by Sutherland and a series of equations were developed to provide estimates of EIA values for input into hydrologic models. The equations varied by using distinctions between the physical characteristics of the development within each of the basins analyzed. The Sutherland EIA equations are summarized as follows:

Extremely disconnected basins, with either extensive infiltration measures or basin serviced predominantly with ditches/swales:

$$
E I A=0.01 \times T I A^{2.8}
$$

Somewhat disconnected basins, either $50 \%$ of urban areas serviced by ditches or swales and roofs disconnected or an average basin with some infiltration measures:

$$
E I A=0.04 \times T I A^{1.7}
$$

Average basins, no infiltration measures, roofs disconnected:

$$
E I A=0.1 \times T I A^{1.5}
$$


Highly connected basins, no infiltration measures, roofs connected:

$$
E I A=0.4 \times T I A^{1.2}
$$

Totally connected basins, no infiltration measures, roofs connected:

$$
E I A=T I A
$$

Dinicola (1989) compiled the work of Alley and Veenhuis, Laenen, and Prysch and Ebbert (1986) and values for EIA were proposed for a range of land uses. However, they were essentially based on Equation 14.1 and not a development of new relationships.

\section{Calibrated computer models}

EIA can be determined by calibrating a physically based computer runoff model such as the US EPA Stormwater Management Model (SWMM) where the many input parameters can be predicted confidently. This method requires extended flow monitoring data to calibrate and validate the EIA values, preferably for a number of events with the full spectrum of expected antecedent conditions for the region.

\subsection{Annual Hydrograph Method to Determine Effective Impervious Area}

To better assess the effectiveness of LID strategies, a fourth method for determining EIA is proposed. This method uses rainfall and flow monitoring data to develop a measured value of EIA for the basin or site, on an annual basis. It is important in many areas to understand what the rainfall-runoff response will be on an annual basis because of the large variability in antecedent conditions that can be expected. The analysis of a single storm event may significantly over or under estimate performance, depending on the antecedent conditions. This is especially true in the coastal areas of western $\mathrm{BC}$ and western Washington where saturated soil conditions exist for a significant portion of the year.

The following sections describe the methodology of the annual hydrograph method and three case studies. 


\subsubsection{Annual Hydrograph Methodology}

The annual hydrograph method to determine EIA is based on the following relationships:

Rainfall Volume $=$ Cumulative Measured Flows +

Losses (Depression Storage, Evaporation, Transpiration, and Groundwater)

Flow Volume from EIA = Cumulative Measured Flows -

Cumulative Flows from Interflow and Shallow Groundwater

Equation 14.8 states that on a volume basis, rainfall must equal runoff plus any losses. This equation can be used to calculate losses from a system due to depression storage, evaporation, transpiration, and infiltration to deep groundwater. Equation 14.9 isolates the portion of the cumulative measured flows in Equation 14.8 that come from the EIA by subtracting the interflow and shallow groundwater from the measured flows. The interflow and shallow groundwater flows can be estimated by one of two methods. The simplest and most cost-effective method is to use an established baseflow separation of the measured flow response, and verify results by inspection using local knowledge of runoff response. The more complex method is to build, calibrate and validate a model such as SWMM that includes groundwater routines. The computer modeling approach will be a more accurate method to remove interflow and shallow groundwater, but at a significantly higher cost.

Rainfall and flow data are plotted as cumulative volumes for the period of record available. It is preferable to analyze one wet and one dry year to obtain an average EIA. The annual hydrograph method depends on the availability of a continuous record of both rainfall and streamflow data. The method should only be used on smaller watersheds where the rainfall is recorded in the watershed boundaries by one or more gauges to reduce the impact of spatial variability. Alternatively, rain gauge data could be corrected with Doppler radar information. This would allow the method to be used for larger watersheds.

\subsubsection{Annual Hydrograph Case Studies}

Three case studies are presented, for three types of drainage areas in the Greater Vancouver area of British Columbia. This area receives high annual volumes of rainfall (ranging from 800 to more than $2000 \mathrm{~mm}$ ) and soil conditions are saturated for a significant portion of the winter ( 3 months). The first case study, 
Chantrell Creek, is a suburban watershed in Surrey, BC. The second, Upper Serpentine River, is a highly developed mixed use watershed in Surrey, BC. The third, the Kerr Wood Leidal Associates (KWL) office roof, is a typical flat roof office building in North Vancouver, BC.

\section{Chantrell Creek}

Chantrell Creek is a 381 ha watershed located within Surrey, BC as shown in Figure 14.1. The watershed is composed primarily of single family residential development with roof leaders typically disconnected and the TIA is estimated to be $30 \%$. The rainfall data used for the annual hydrograph analysis is from a rain gauge located in the middle of the watershed at the Chantrell Creek Elementary School. The streamflow station used for the analysis is located on Chantrell Creek at $32^{\text {nd }}$ Avenue. The City of Surrey has had a policy of roof leader disconnection within the watershed. Roof area in single-family lot typically comprises $30 \%$ to $50 \%$ of the lot area. Disconnection of the roof leaders should significantly reduce the EIA.

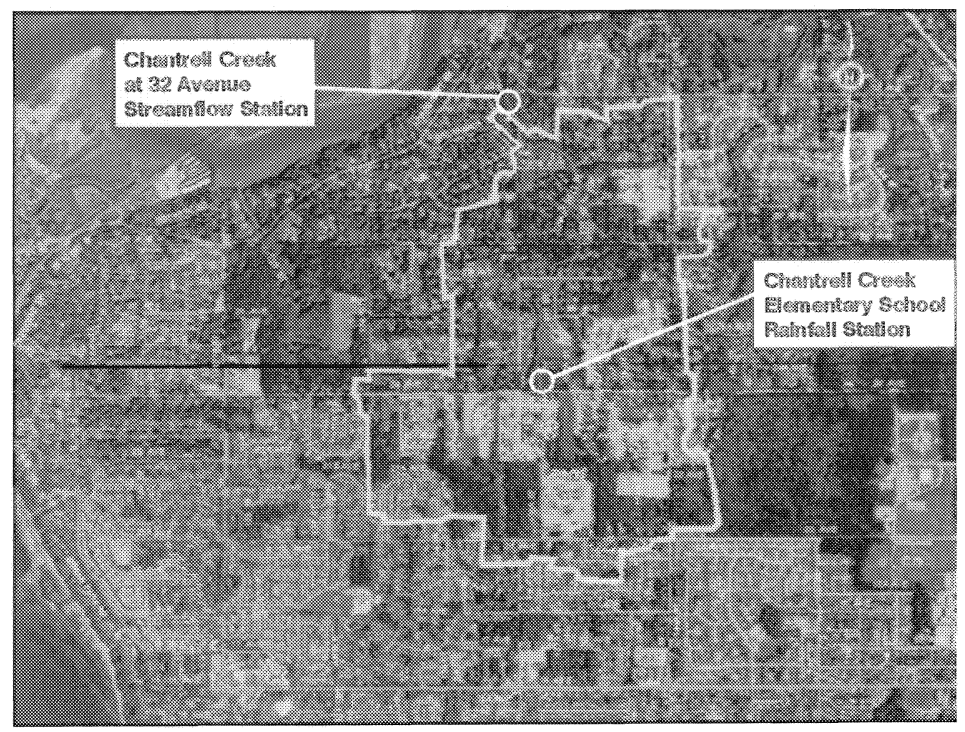

Figure 14.1 Chantrell Creek watershed.

The following figure (Figure 14.2) shows the rainfall and streamflow data from 2000 for the Chantrell Creek watershed. 


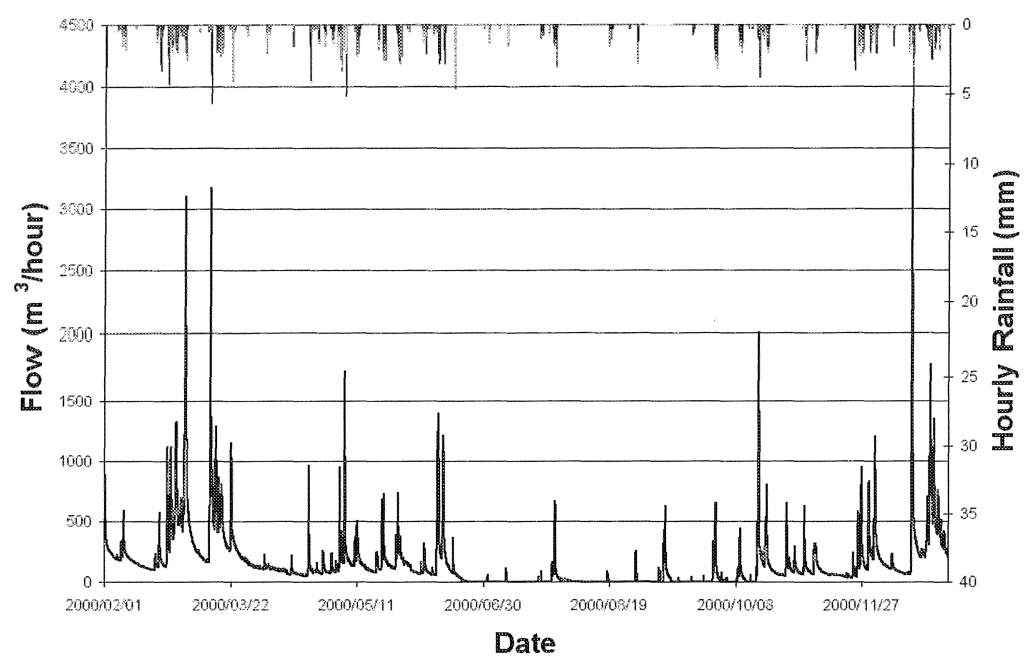

Figure 14.2 Chantrell Creek rainfall and flow annual hydrograph.

Plotting this data on a cumulative volume basis results in the plot shown in Figure 14.3. The difference between rainfall and runoff amounts to approximately $55 \%$. As described in Equation 14.8, this 55\% is attributable to evaporation, transpiration, and deep groundwater.

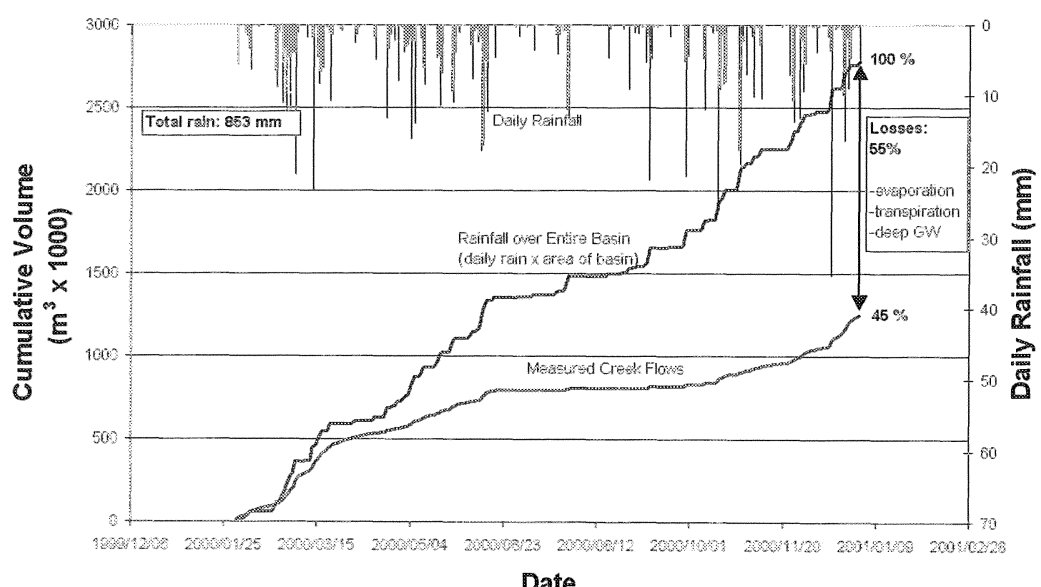

Figure 14.3 Chantrell Creek cumulative volumes. 
The interflow and shallow groundwater is then subtracted from the streamflow using the constant-slope method for baseflow separation. This assumes that interflow and shallow groundwater are equal to the streamflow after a rainfall event has passed, and rises linearly during a rainfall event until reaching an inflection point on the recession limb of the storm hydrograph. Figure 14.4 shows the estimate of the interflow and shallow groundwater in comparison to the measured creek flows for some small events.

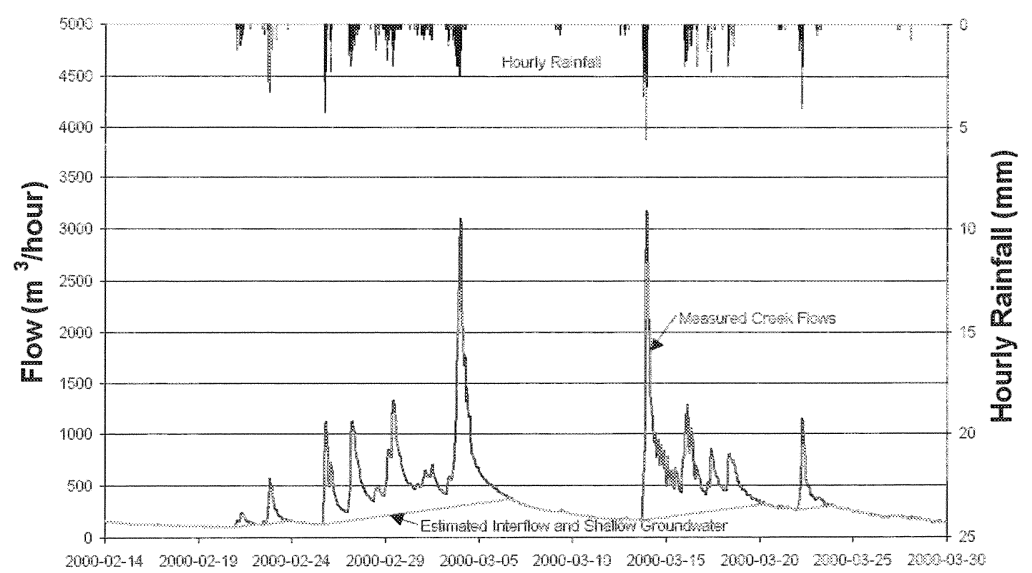

Date

Figure 14.4 Chantrell Creek estimate of interflow and shallow groundwater.

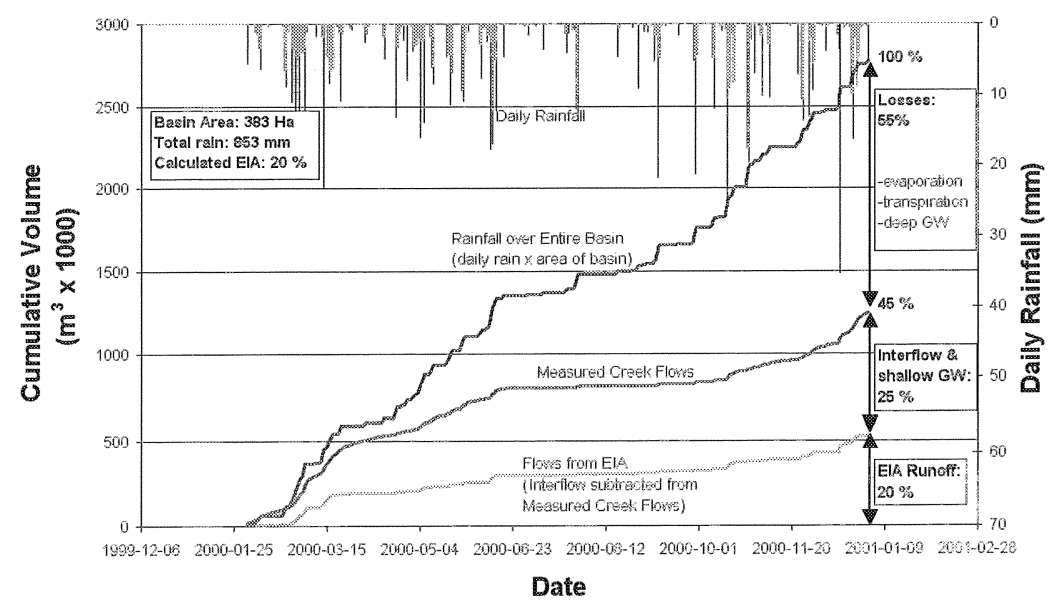

Figure 14.5 Chantrell Creek annual hydrograph EIA. 
After removing the interflow and shallow groundwater volume from the streamflow volume, Figure 14.5 shows the estimated flows from the EIA.

The EIA for Chantrell Creek is therefore estimated to be $20 \%$ using the annual hydrograph method, which is significantly less than the 30\% TIA estimated from the air photo. This indicates that a reduction in runoff does occur, despite the presence of saturated soil conditions for a significant portion of the year. The LID strategy of disconnecting roof leaders to front lawns does appear to be effective.

\section{Upper Serpentine River}

The Upper Serpentine River is a 240 ha watershed located in Surrey, BC as shown in Figure 14.6. The watershed is composed of a mix of single family residential, commercial, and light industrial with no known LID strategies within the watershed. The TIA for the Upper Serpentine River is estimated to be $66 \%$. The rainfall data used for the annual hydrograph analysis is from the GVRD Whalley rainfall station. The streamflow station used in the analysis is located on the Serpentine River at $104^{\text {th }}$ Street.

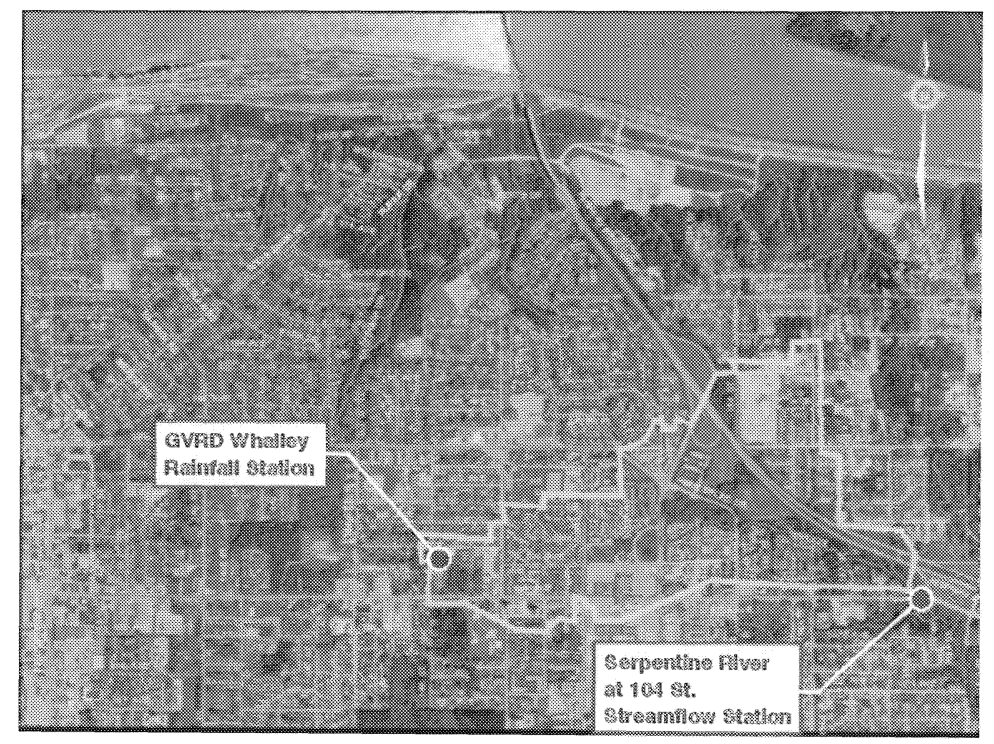

Figure 14.6 Upper Serpentine River watershed.

Two years of data, 1999 and 2000, were analyzed to determine an EIA for the Upper Serpentine River basin, and the results are shown in Figure 14.7. 


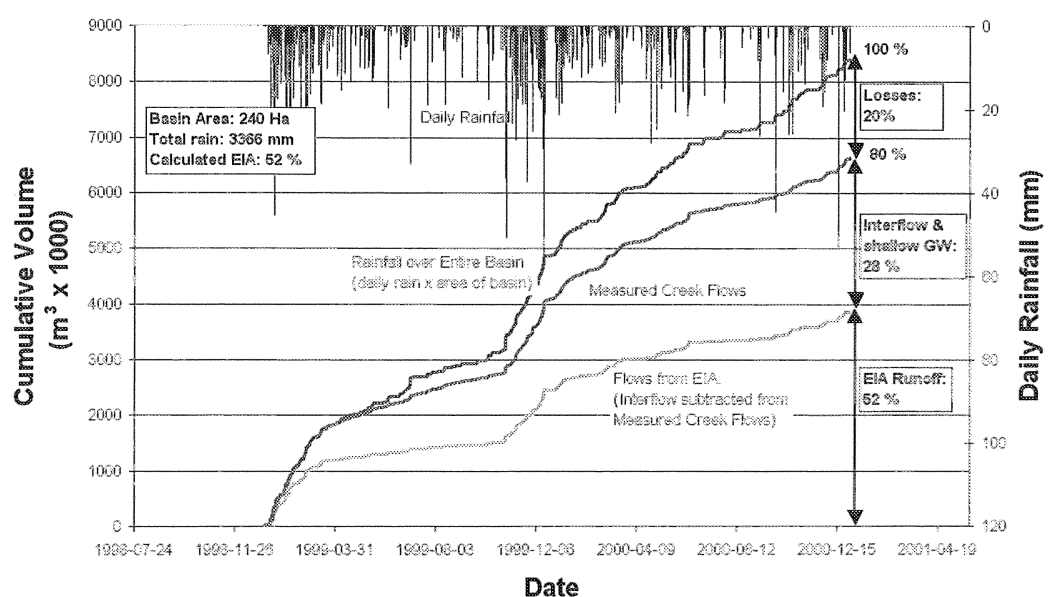

Figure 14.7 Upper Serpentine River annual hydrograph EIA.

The results for 1999 estimated an EIA of 51\%, and for 2000 an EIA of $53 \%$, for a two-year average of $52 \%$, which again is less than the TIA of $66 \%$. Although there are no documented LID strategies within the watershed, a significant portion of the TIA is occupied by roof area, particularly flat roofs. It is believed that the real EIA of the roof area is less than the calculated TIA, and this difference may be the main reason why the EIA of the watershed is $13 \%$ less than the TIA. This is discussed further in the next case study.

A typical summer and winter month were selected from the two years plotted in Figure 14.7. An analysis of a winter month, January 1999, resulted in an EIA of 66\%, equal to the TIA and greater than the annual EIA. An analysis of a summer month, July 2000 , showed an EIA of $25 \%$, significantly lower than both the TIA and the annual EIA. This analysis confirms expectations and suggests that little or no infiltration occurs in the winter due to saturated soils and more significant infiltration occurs during the summer, even with a relatively high TIA watershed. This difference between the seasons can also be seen by inspection of the slopes of the cumulative volume lines in Figure 14.7. During the winter the slopes of the EIA flow line and the measured creek flow line are similar, while in the summer the EIA flow line has a much flatter slope than the measured creek flow line.

\section{KWL office roof}

The KWL office roof is 0.0325 ha flat tar and gravel roof located within North Vancouver, BC as shown in Figure 14.8. The roof is typical of many similar flat roof buildings in the area and has been the focus of an initiative to retrofit with 
a green roof. As a result, the response to rainfall has been monitored as the pregreen roof condition. The TIA for the KWL Office Roof is $100 \%$. The rainfall data used for the annual hydrograph analysis is from a rain gauge located on the middle of the roof. The flow monitoring data is collected using a weir installed in the roof drainage sump.

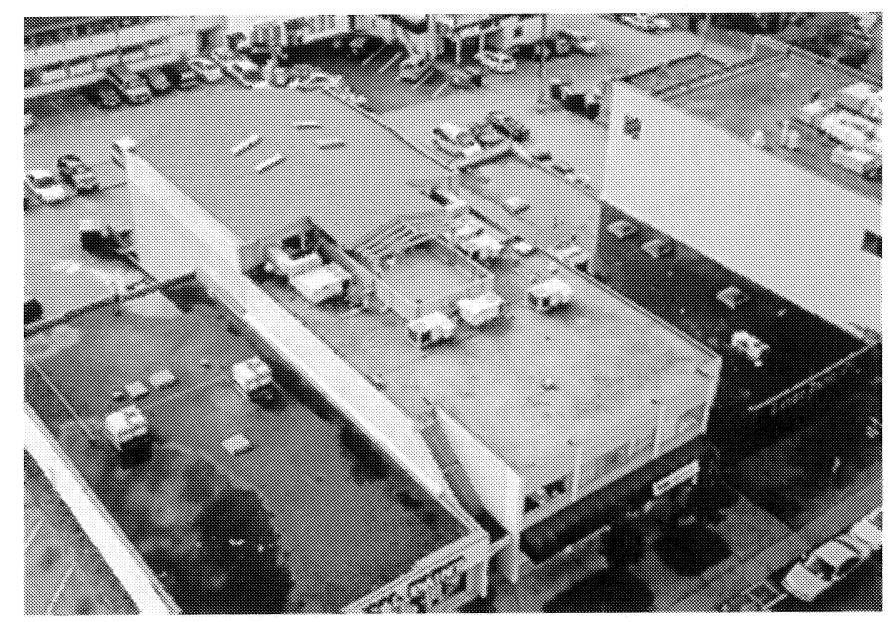

Figure $14.8 \mathrm{KWL}$ office roof.

The following figure shows the results of the data collected.

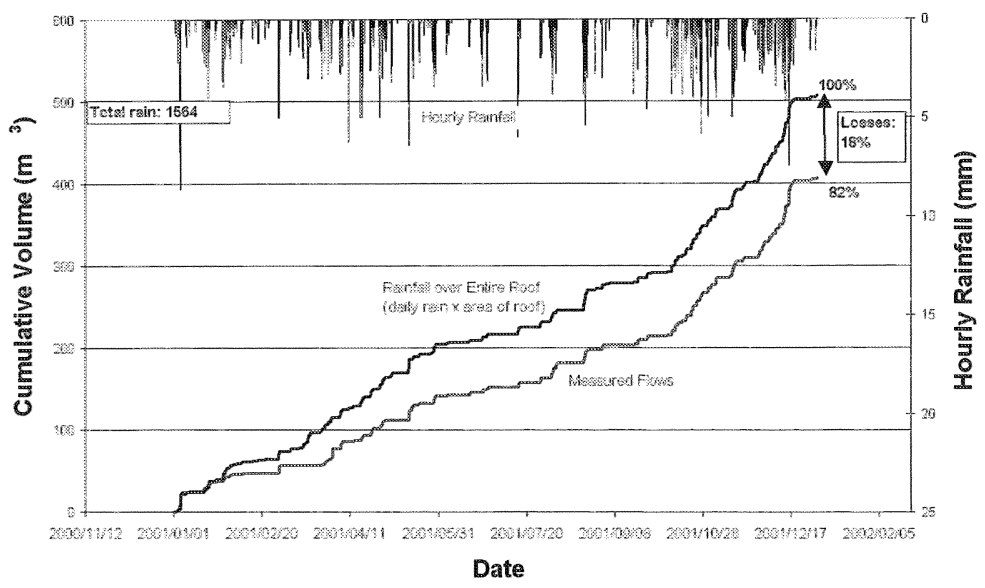

Figure 14.9 KWL office roof annual hydrograph EIA. 
Figure 14.9 shows lower volumes running off the roof than would be computed using the TIA of $100 \%$. This reduction is attributable to the storage in the gravel and subsequent evaporation. Therefore the EIA for this roof is $82 \%$ and the tar and $30 \mathrm{~mm}$ gravel roof behaves like a partial LID strategy, even without implementing the green roof. The annual hydrograph method provides an effective way to assess the performance of sites such as the KWL Office Roof.

\section{Comparison of results}

The three case studies were examined using the empirical equations for determining EIA and the results then compared to the results from the annual hydrograph method. The following table summarizes the results:

\begin{tabular}{lcccc} 
Case Study & TIA & $\begin{array}{c}\text { EIA } \\
\text { Alley and } \\
\text { Veenhuis }\end{array}$ & $\begin{array}{c}\text { EIA } \\
\text { Sutherland }\end{array}$ & $\begin{array}{c}\text { EIA } \\
\text { Annual } \\
\text { Hydrograph }\end{array}$ \\
\hline $\begin{array}{l}\text { Chantrell Creek } \\
\begin{array}{l}\text { Upper } \\
\text { Serpentine }\end{array}\end{array}$ & $30 \%$ & $18 \%$ & $16 \%$ & $20 \%$ \\
$\begin{array}{l}\text { River } \\
\text { KWL Office }\end{array}$ & $66 \%$ & $55 \%$ & $60 \%$ & $52 \%$ \\
Roof & $100 \%$ & $99 \%$ & $100 \%$ & $82 \%$ \\
\hline
\end{tabular}

From this comparison, it can be seen that the EIA equations provide similar results to the annual hydrograph method, with the exception of the KWL Office Roof. The empirical equations appear to significantly over-estimate the EIA when the TIA is high at this particular site. This result is not surprising, in part because the other methods were developed to estimate EIA for watersheds and not for small, isolated sites.

\subsection{Conclusions}

The benefits of using the annual hydrograph method are:

- it can be used without developing a complex watershed computer model;

- it can be used to assess the performance of LID strategies at both the site and the watershed level; and

- it provides a reasonable estimate of the year-round EIA for the range of antecedent soil moisture levels found throughout the year. 
Where a year of streamflow and rainfall data are available, we believe that the annual hydrograph method is more accurate because it uses site or watershed specific data that truly represent existing conditions. In addition, this method can be used for watersheds where the type of development and the type of LID strategies that may have been included during development are unknown.

Furthermore, the annual hydrograph method of EIA determination could be used to develop additional relationships for all LID strategies. This should provide stormwater management planning professionals with additional tools to assist in making the decisions that will improve watershed health.

\subsection{Summary}

The following is a summary of the main points of this chapter:

- EIA is an important parameter for computing watershed health, understanding the rainfall-runoff response, and calibrating continuous simulations of rainfall-runoff.

- The annual hydrograph method is a valuable tool to determine EIA more accurately and on an annual basis.

- EIA exists in coastal areas, even with saturated soils for a significant portion of the winter.

- The annual hydrograph method is an effective way to assess the performance of LID strategies, especially in regions where antecedent conditions vary throughout the year.

- Tar and gravel roofs with poor drainage can perform like a partial LID strategy.

- The annual hydrograph method can be used to develop performance relationships for all LID strategies.

\section{References}

Alley, W.M., and Veenhuis, J.E., 1983. Effective Impervious Area in Urban Runoff Modeling. Journal of Hydraulic Engineering Vol. 109, No. 2, pp. 313- 319.

Dinicola, R. S., 1989. Characterization and simulation of rainfall-runoff relations for headwater basins in western King and Snohomish Counties, Washington State. U. S. Geological Survey Water-Resources Investigation Report 89-4052, 52 pp. Schueler, T., 1995. The Importance of Imperviousness. Watershed Protection 
Techniques, 1(3): 100-111.

Laenen, A., 1983. Storm runoff as related to urbanization based on data collected in Salem and Portland, and generalized for the Willamette Valley, Oregon. U. S. Geological Survey Water-Resources Investigations Report 83-4143.

Prysch, E. A., and Ebbert, J. C., 1986. Quantity and quality of storm runoff from three urban catchments in Bellevue, Washington. U. S. Geological Survey WaterResources Investigations Report 86-4000, 85 pp.

Sutherland, R. Methods for Estimating the Effective Impervious Area of Urban Watersheds. Watershed Protection Techniques, 2(1): 282-284.

Zandbergen, P. and Schreier, H., 2000. Comparative Analysis of Methodologies for Measuring Watershed Imperviousness. Watershed Management 2000 Conference, July 2000. 